\title{
PENINGKATAN USAHA UKM KERUPUK PULI MELALUI PELATIHAN DAN PENDAMPINGAN MANAJEMEN PENGEMASAN PRODUK
}

\section{IMPROVING PULI CRACKER SME BUSINESS THROUGH PRODUCT PACKAGING MANAGEMENT TRAINING AND ASSISTANCE}

\author{
Chandra Sundaygara, Riski Nur Istiqomah Dinnullah* \\ Universitas Kanjuruhan Malang, Jln. S. Supriyadi 48 Malang \\ *Email:ky2_zahra@unikama.ac.id \\ (Diterima 17-05-2021; Disetujui 13-08-2021)
}

\begin{abstract}
ABSTRAK
Kerupuk puli merupakan produk makanan berbahan dasar beras yang sangat digemari oleh masyarakat. Kerupuk ini mudah dijumpai dimana saja. Selain harganya yang murah, kerupuk ini banyak disukai masyarakat karena rasanya gurih dan mudah didapat. Hal inilah yang menjadikan masyarakat banyak membuka peluang usaha dengan menjual kerupuk puli tersebut. Beberapa diantara UKM yang telah mengelola usaha pembuatan kerupuk puli ini adalah UKM milik Ibu Yati yang bertempat di Kelayatan Gang 2, RT 10, RW 12 Desa Sukun, Kecamatan Sukun, Kota Malang, Jawa Timur. Pemilik UKM tersebut menjadi mitra dalam kegiatan PKM ini. Permasalahan yang ada pada mitra ini adalah proses pengemasan yang kurang baik. Selama ini mitra menggunakan lilin dalam mengemas kerupuk puli yang telah dikemas dalam plastik. Kurang merekatnya plastik yang direkatkan tersebut menyebabkan kerupuk terkontaminasi dengan udara luar sehingga mudah melempem dan menjadi kurang higienis. Oleh karena itu, tujuan dari diadakannya kegiatan pengabdian masyarakat ini adalah memberikan pendampingan dan pelatihan manajemen pengemasan produk kerupuk puli kepada mitra UKM Kerupuk Puli. Metode yang digunakan adalah transfer ilmu pengetahuan terkait dengan desain merek dagang maupun manajemen pengemasan yang menarik kepada pemilik usaha. Hasil dari kegiatan ini adalah mitra memiliki tambahan pengetahuan terkait pengemasan produknya agar lebuh baik dan menarik serta mampu membuat merek dagang sederhana. Sementara, dampak positif yang terjadi setelah dilakukan kegiatan ini adalah mitra mampu menghasilkan produk kerupuk puli yang lebih berkualitas dikarenakan dengan proses pengemasan yang baik kemasan kerupuk tidak akan mudah bocor sehingga kerupuk tidak mudah melempem (tetap renyah).
\end{abstract}

Kata kunci: Kerupuk Puli, Manajemen Pengemasan, Merek Produk

\begin{abstract}
Puli crackers are rice-based food products that are very popular with the community. These crackers are easy to find anywhere. In addition to the cheap price, these crackers are liked by many people because they are delicious and easy to get. This is what makes many people open up business opportunities by selling these puli crackers. Some of the UKM that have managed this puli cracker-making business are the UKM owned by Mrs. Yati which are located in Kelayatan Gang 2, RT 10, RW 12 Kecamatan Sukun, Malang City, East Java. The UKM owner becomes a partner in this PKM activity. The problem with this partner is the poor packaging process. Partners have used candles in packing Puli crackers that have been packaged in plastic. The lack of adhesiveness of the glued plastic causes the crackers to be contaminated with outside air so that they easily become sluggish and less hygienic. The purpose of holding this community service activity is to provide assistance and training on packaging management. The method used is the transfer of knowledge related to trademark design and attractive packaging management to business owners. The result is UKM have additional knowledge related to packaging their products so that they are better and more attractive and be able to create simple trademarks. The positive impact was that partners were able to produce higher quality Puli cracker products because with a good packaging process the cracker packaging would not leak easily so that the crackers stay crunchy.
\end{abstract}

Keywords: Puli Crackers, Packaging Management, Trademark 


\section{PENDAHULUAN}

Kerupuk adalah produk kering yang diperoleh dari tapioka atau tepung lain, dengan atau tanpa penambahan bahan lain, sesuai dengan jenis makanan. Kerupuk menjadi makanan ringan khas Indonesia yang sangat dikenal dan digemari oleh masyarakat. Konsumsi kerupuk bukanlah sebagai makanan utama melainkan sebagai makanan pendamping atau lauk karena rasanya yang gurih dan enak yang dapat menambah selera makan (Rosiani, Basito, \& Widowati, 2015). Salah satu kerupuk yang banyak dijumpai dimasyarakat adalah kerupuk puli.

Kerupuk puli ini dibuat dari adonan tepung tapioka dan mengandung pati yang cukup tinggi. Kerupuk sangat beragam dalam bentuk, ukuran, warna, bau, rasa, kerenyahan, ketebalan ataupun nilai gizinya. Kerupuk puli tradisional umumnya mempunyai warna kecoklatan dan pada umumnya menggunakan tapioka sebagai patinya (Karjo, Suseno, \& Utomo, 2015). Dalam proses pembuatannya, selain bawang putih yang digunakan sebagai penyedap, juga masih ada bahan tambahan yaitu garam bleng (Hariyani, 2018).

Kerupuk yang banyak digemari oleh masyrakat ini, membuka peluang bisnis bagi banyak industri rumahan untuk mengelola usaha penjualan kerupuk puli. Beberapa diantara UKM yang telah mengelola usaha pembuatan kerupuk bawang ini adalah UKM milik Ibu Yati yang bertempat di Kelayatan Gang 2, RT 10, RW 12 Desa Sukun, Kecamatan Sukun, Kota Malang, Jawa Timur.

Pemasaran dilakukan secara langsung dengan mendatangi tempat penjualan di warung, toko, kantin sekolah dan pabrik dengan dibantu oleh reseller. Karena produk kerupuk ini banyak yang di titipkan di kantin sekolah, sehingga penjualan dapat meningkat saat anak sekolah masuk, namun saat liburan sekolah produk kerupuk yang terjual hanya sedikit. Namun, berbeda halnya dengan kerupuk yang dititipkan di warung, toko dan kantin pabrik. Di tempat-tempat tersebut hampir setiap hari kerupuk yang dikirimkan habis terjual.

Proses pembuatan kerupuk bawang terdiri dari empat tahap, yaitu tahap pembuatan dan pengukusan adonan, pengirisan lontong kerupuk, penjemuran dan penggorengan. Bahan dasar pembuatan makanan ini adalah tepung tapioka. Dalam pembuatan adonan dibutuhkan waktu sekitar \pm 35-40 menit. Untuk bahan baku, tidak terdapat masalah yang signifikan. Karena bahan baku pembuatan kerupuk ini mudah didapat dan harganya terjangkau dipasaran. Setiap hari, UKM milik Ibu Yati memproduksi sekitar $15 \mathrm{~kg}$ kerupuk dan proses pengemasan dilakukan dengan alat sekadarnya yaitu menggunakan lilin. Kerupuk puli milik Ibu Yati memiliki banyak peminat namun dari pelanggan sering 
mengeluhkan bahwa kerupuk yang dibeli terkadang ada yang melempem sehingga pelanggan sering menukarkan kembali kerupuk yang melempem tersebut karena tidak laku jika dijual kembali. Hal ini tentunya sangat merugikan bagi mitra. Oleh karena itu, tujuan dilaksanakan kegiatan pengabdian ini adalah memberikan pelatihan dan pendampingan manajemen pengemasan produk kerupuk puli yang baik serta menarik. Melalui kegiatan tersebut, diharapkan dapat meningatkan kualitas produk mitra serta mampu meningkatkan penjualan usaha mitra.

\section{BAHAN DAN METODE}

Kegiatan ini dilaksanakan pada Bulan Mei - Juni 2021 yang bertempat dikediaman Ibu Yati sebagai pemilik usaha yaitu di Kelayatan Gang 2, RT 10, RW 12 Desa Sukun, Kecamatan Sukun, Kota Malang, Jawa Timur. Dalam pelaksanaannya akan dihadiri oleh 4 orang karyawan.

Metode pelaksanaan yang akan dilakukan untuk menyelesaikan permasalahan pemilik usaha ini dapat dilihat pada gambar berikut ini.

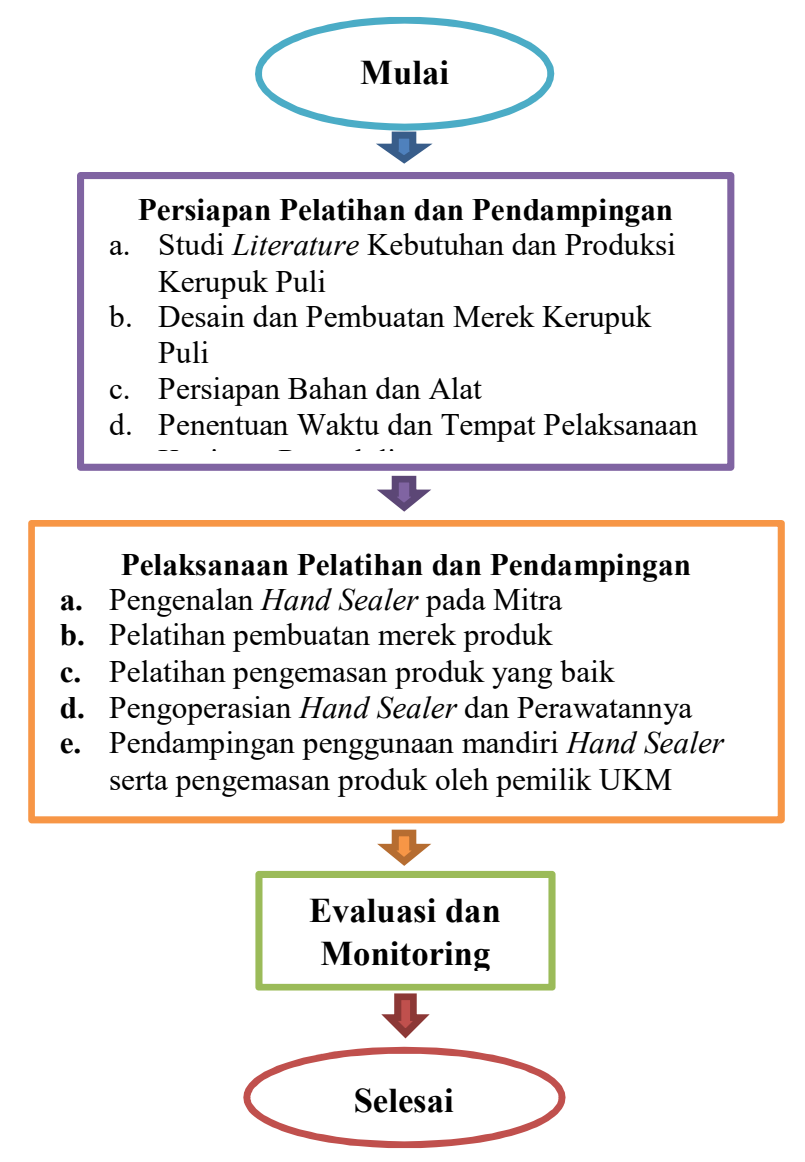

Gambar 1. Diagram Alir Pelaksanaan Kegiatan

Dari diagram di atas dapat dıjelaskan rencana kegıatan yang akan dilakukan antara lain sebagai berikut: 


\section{A. Persiapan Pelatihan dan Pendampingan}

Tahap awal persiapan pelatihan dan pendampingan ini dimulai dengan studi literature mengenai kebutuhan dan proses produksi kerupuk puli, proses desain dan pembuatan merek produk sebagai ciri khas dari UKM kerupuk tersebut. Selanjutnya, mempersiapkan alat dan bahan-bahan yang akan digunakan pada saat pelatihan dan proses pendampingan. Alat untuk proses pengemasan ini adalah hand sealer yang digunakan untuk merekatkan plastik kemasan kerupuk. Sementara alat dan bahan lainnya seperti plastik, kerupuk puli, dan baskom plastik telah disiapkan oleh mitra. Hal yang tidak kalah pentingnya adalah komunikasi dengan mitra sebagai sasaran dari kegiatan ini dalam keikutsertaannya pada kegiatan pelatihan terutama dalam menentukan waktu dan tempat pelaksanaan pelatihan.

\section{B. Pelaksanaan Worksop dan Pendampingan}

Kegiatan pelatihan dan pendampingan dilakukan untuk melatih mitra dalam mengoperasikan Hand Sealer secara langsung beserta perawatan dan trouble shooting. Kegiatan selanjutnya adalah memberikan pelatihan tentang manajemen pengemasan yang baik dan menarik. Hal ini dilakukan agar produksi kerupuk puli mitra memiliki kualitas lebih baik sehingga mampu memiliki daya saing lebih tinggi dari produk sejenisnya. Trainer yang akan mengisi kegiatan worksop dan pendampingan ini adalah Tim Pengabdi yang memiliki kompetensi sesuai kebutuhan mitra.

Tabel 1. Materi Kegiatan dan Pemateri

\begin{tabular}{clc}
\hline No & \multicolumn{1}{c}{ Materi } & \multicolumn{1}{c}{ Pemateri } \\
\hline 1 & Pengenalan Hand Sealer & Chandra Sundaygara, M.Pd. \\
\hline 2 & $\begin{array}{l}\text { Pelatihan Pengoperasian Hand } \\
\text { Sealer }\end{array}$ & Chandra Sundaygara, M.Pd. \\
\hline 3 & Pelatihan Desain Merek Produk & Chandra Sundaygara, M.Pd. \\
\hline 4 & $\begin{array}{l}\text { Pelatihan Manajemen } \\
\text { Pengemasan }\end{array}$ & Riski Nur I. D., M.Si. \\
\hline 5 & $\begin{array}{l}\text { Pendampingan pengoperasian } \\
\text { mandiri oleh mitra bersama tim }\end{array}$ & Riski Nur I. D., M.Si. \\
\hline 6 & $\begin{array}{l}\text { Pelatihan dan pendampingan } \\
\text { pengoperasi mesin secara } \\
\text { mandiri oleh pemilik usaha }\end{array}$ & Riski Nur I. D., M.Si. \\
\hline
\end{tabular}

\section{Partisipasi dari UKM Kerupuk}

Dalam kegiatan ini seluruhnya melibatkan partisipasi dari mitra secara langsung. Mitra telah sanggup untuk menyediakan waktu dan tempat serta bahan-bahan dan peralatan 
yang digunakan dalam produksi kerupuk puli. Model yang digunakan dalam kegiatan ini adalah model partisipasi penuh dari mitra yang dimaksudkan untuk menanamkan rasa kepemilikan serta membantu mitra dalam meningkatkan hasil produksi kerupuk. Dengan partisipasi penuh ini, diharapkan kedepannya dapat membantu mitra untuk menghasilkan omzet yang lebih besar secara berkelanjutan.

\section{Monitoring dan Evaluasi}

Tahap monitoring dan evaluasi dilakukan agar proses keberlanjutan oleh mitra yang tentunya masih membutuhkan pembimbingan dalam proses pelaksanaan program. Tahap ini akan dilaksanakan bersama mitra setiap tiga bulan sekali setelah dilaksanakannya program. Maka dari itu, tujuan dari tahap ini antara lain:

a. Melihat perkembangan program yang telah dilaksanakan.

b. Mengetahui kendala yang ada dalam proses pelaksanaan program.

c. Mencari solusi terhadap masalah yang ada.

Proses monitoring dan evaluasi ini akan dilakukan oleh tim pegabdi bersama mitra. Dengan demikian, kendala maupun kekurangan yang terjadi dalam pelaksanaan program dapat diperbaiki menjadi lebih baik sehingga program yang dilaksanakan benar-benar efektif dan maksimal serta bersinergis.

\section{HASIL DAN PEMBAHASAN}

Dalam kegiatan ini tim pengabdian memberikan Hand Sealer yang akan memudahkan mitra dalam proses pengemasan produk kerupuk puli.

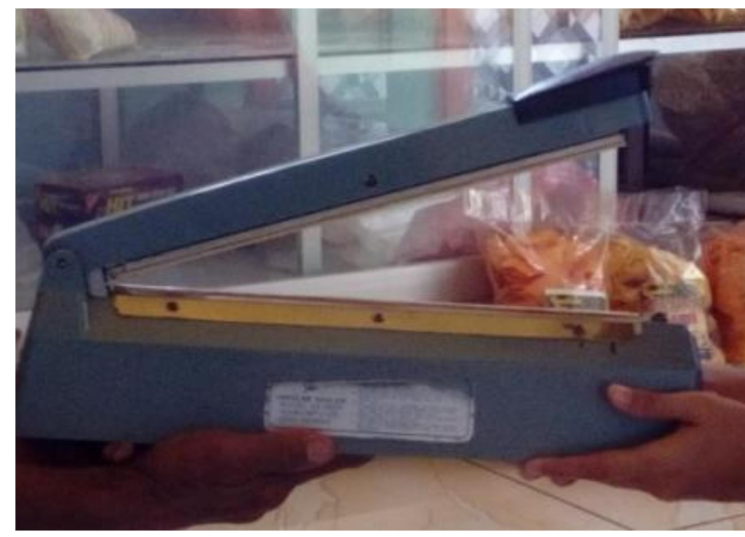

Gambar 2. Hand Selaer

Spesifikasi hand sealer diberikan sebagai berikut
a. Tipe
: Side Cutter Model.
b. Model
: PCS200C. 
c. Impulse Power : 300W.

d. Seal Length $\quad: 200 \mathrm{~mm}$.

e. Seal Width $\quad: 2 \mathrm{~mm}$.

f. Machine Weight : $2.7 \mathrm{~kg}$.

Sementara, hasil pelaksanaan kegiatan diberikan sebagai berikut

Tabel 2. Hasil Kegiatan Pengabdian

\begin{tabular}{|c|c|c|c|}
\hline No & Kegiatan Pengabdian & $\begin{array}{c}\text { Tanggal } \\
\text { Pelaksanaan }\end{array}$ & Hasil Kegiatan \\
\hline 1 & Pengenalan Hand Sealer & 24 Mei 2021 & $\begin{array}{l}\text { Dari kegiatan ini, mitra } \\
\text { mengetahui alat-alat dan bahan } \\
\text { yang dapat digunakan dalam } \\
\text { mengemas produknya gar } \\
\text { lebih baik }\end{array}$ \\
\hline 2 & $\begin{array}{l}\text { Pelatihan Pengoperasian Hand } \\
\text { Sealer }\end{array}$ & 26 Mei 2021 & $\begin{array}{l}\text { Mitra mengetahui cara } \\
\text { penggunaan dan perawatan } \\
\text { alat dengan baik }\end{array}$ \\
\hline 3 & $\begin{array}{l}\text { Pelatihan Desain Merek } \\
\text { Produk }\end{array}$ & 31 Mei 2021 & $\begin{array}{l}\text { Mitra telah mengetahui } \\
\text { pembuatan desain merek } \\
\text { sederhana dengan } \\
\text { munggunakan aplikasi mobile }\end{array}$ \\
\hline 4 & $\begin{array}{l}\text { Pelatihan Manajemen } \\
\text { Pengemasan }\end{array}$ & 3 Juni 2021 & $\begin{array}{l}\text { Mitra memahami cara } \\
\text { mengemas yang baik dan } \\
\text { menarik }\end{array}$ \\
\hline 5 & $\begin{array}{l}\text { Pendampingan pengoperasian } \\
\text { alat secara mandiri oleh mitra } \\
\text { bersama tim }\end{array}$ & 7 Juni 2021 & $\begin{array}{l}\text { Mitra telah mampu } \\
\text { menggunakan hand sealer } \\
\text { dengan mandiri dan alat ini } \\
\text { juga telah digunakan untuk } \\
\text { mengemas banyak produk } \\
\text { kerupuk puli mitra }\end{array}$ \\
\hline 6 & $\begin{array}{l}\text { Evaluasi Kegiatan antara tim } \\
\text { bersama mitra }\end{array}$ & 9-10 Juni 2021 & $\begin{array}{l}\text { Dari hasil diskusi bersama saat } \\
\text { monitoring dan evaluasi } \\
\text { terdapat beberapa kendala, } \\
\text { namun telah diselesaikan } \\
\text { bersama }\end{array}$ \\
\hline
\end{tabular}

Kegiatan pengabdian ini diikuti oleh 5 orang karya beserta pemilik UKM. Dari kegiatan ini adapat dilihat bahwa mitra dan karyawannya sangat antusias dalam mengikuti kegiatan tersebut. Hal ini dapat diketahui dari semangat peserta yang banyak memberikan pertanyaan ketika mereka kurang memahami apa yang disampaikan oleh pemateri. Pada kegiatan ini juga diberikan manual book sederhana cara penggunaan hand sealer beserta perawatannya agar alat dapat awet digunakan (tidak mudah rusak). 


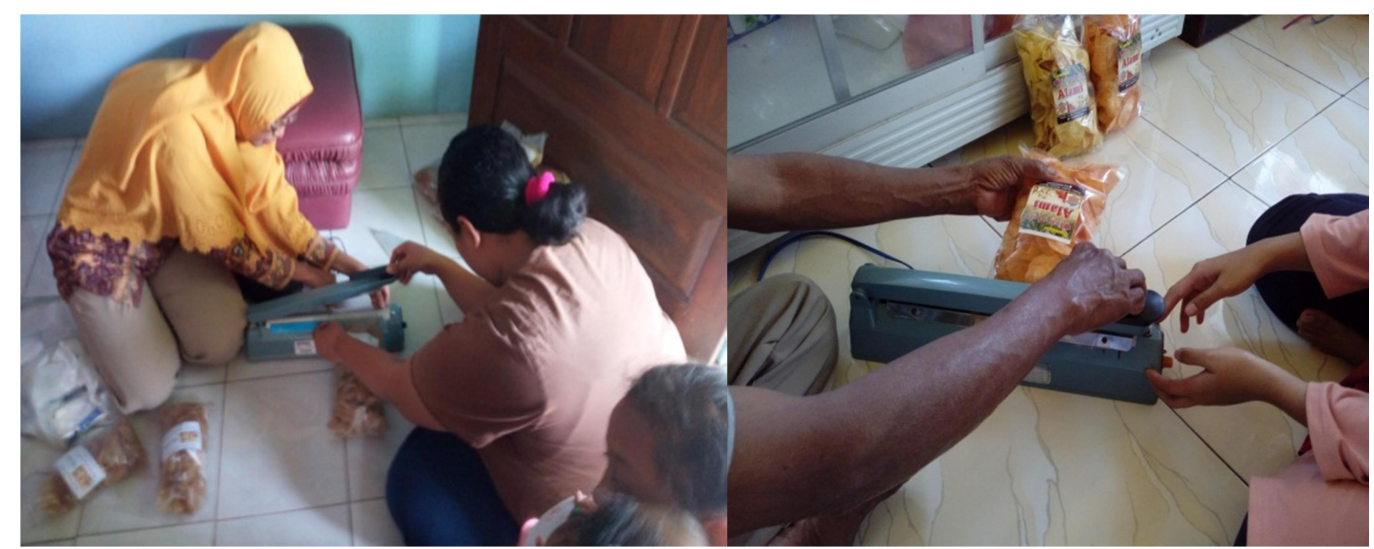

Gambar 3. Pelatihan dan Pendampingan Pengemasan dengan Menggunakan Hand Sealer

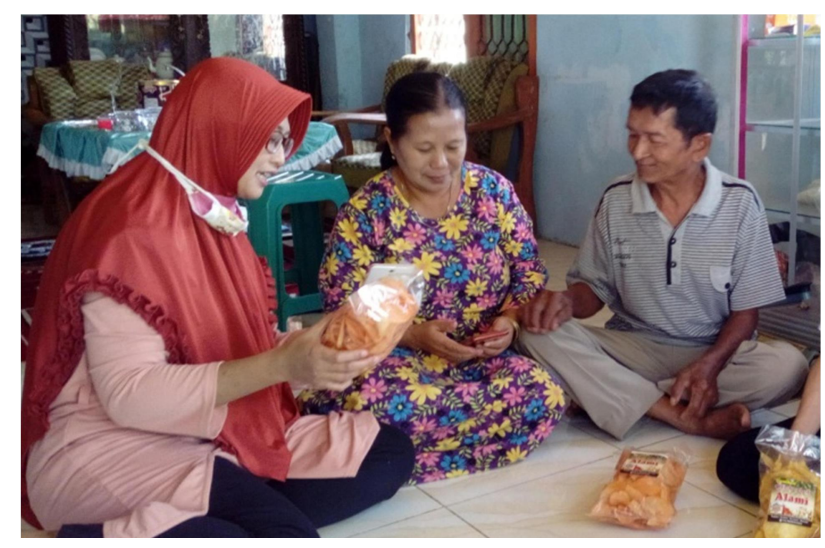

Gambar 4. Pelatihan Pembuatan Desain Merek Produk secara Mobile

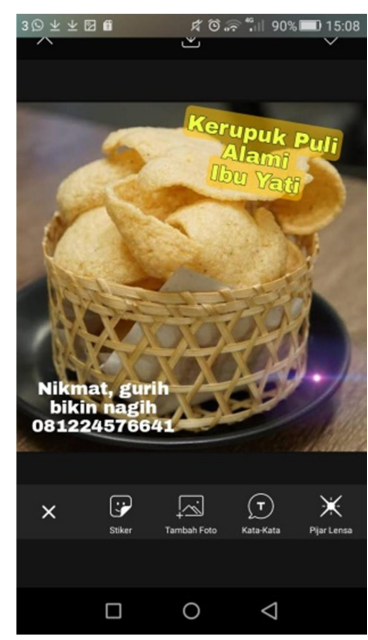

Gambar 5. Tampilan Desain Merek Produk

Penggunaan hand sealer dalam packing process produk sangat penting untuk diperhatikan terutama pada produksi kerupuk yang telah matang. Hal ini sejalan dengan kegiatan pengabdian yang telah dilakukan oleh (Dinnullah, Nurdin, \& Sumadji, 2018) yang 
mengatakan bahwa selain mampu mempertahankan kualitas produk, adanya desain menarik yang ditampilkan dari proses pengemasan mampu meningkatkan penjualan produk yang dihasilkan. Sementara, pengabdian (Fitriani et al., 2020) menunjukkan bahwa pemberian label dapat memberikan informasi kepada konsumen. Begitu pula pada pengabdian pada UK Kerupuk Puli ini, pemberian merek pada kemasan tentunya mampu mengenalkan kepada masyarkat luas tentang usaha yang dikembangkan oleh mitra.

Selanjutnya, dari kegiatan ini tentunya memberikan dampak positif bagi pengembangan usaha mitra. Dampak tersebut antara lain.

Tabel 3. Dampak Positif dari Kegiatan

\begin{tabular}{|c|c|c|c|}
\hline No & Masalah & Sebelum Kegiatan & Sesudah Kegiatan \\
\hline 1 & Pengetahuan Pengemasan & $\begin{array}{l}\text { Mitra menggunakan } \\
\text { lilin untuk mengemas } \\
\text { produk kerupuk puli }\end{array}$ & $\begin{array}{l}\text { Mitra menggunakan hand } \\
\text { sealer dalam proses } \\
\text { pengemasan produknya }\end{array}$ \\
\hline 2 & Keterampilan Mitra & $\begin{array}{l}\text { Mitra belum mengerti } \\
\text { dalam hal pembuatan } \\
\text { merek produk }\end{array}$ & $\begin{array}{l}\text { Mitra dapat membuat merek } \\
\text { produk sederhana sendiri }\end{array}$ \\
\hline & Kualitas produk & $\begin{array}{l}\text { Krupuk mitra banyak } \\
\text { yang dikembalikan } \\
\text { pelanggan karena tidak } \\
\text { renyah } \\
\text { (melempem). }\end{array}$ & $\begin{array}{l}\text { Kerupuk terjamin } \\
\text { kualitasnya karena udara } \\
\text { tidak dapat masuk lagi ke } \\
\text { dalam plastik. }\end{array}$ \\
\hline
\end{tabular}

Sementara itu, berdasarkan evaluasi dan monitoring yang dilakukan setelah kegiatan pengabdian ini dilaksanakan, mitra mengungkapkan beberapa kendala yang dihadapi antara lain:

a. Ketika menggunakan hand sealer, hasil rekatan kurang rapi dan terkadang plastik menjadi leleh.

b. pengemasan agak susah ketika plastik terkena minyak dari kerupuk yang telah dimasukkan.

c. Pesaing dengan kuliner sejenis semakin banyak, sementara mitra belum memiliki pemasaran secara online.

d. Mitra belum memiliki pembukuan keuangan usaha.

Melalui diskusi bersama mitra dengan tim pengabdi diperoleh penyelesaian masalah tersebut antara lain: 
a. Mitra perlu belajar kembali cara untuk menyetel tingkat panas pada hand sealer agar tepat saat digunakan.

b. Mitra telah memesan alat peniris minyak, sehingga mampu mengurangi minyak yang berlebihan dari kerupuk yang telah digoreng.

c. Mitra perlu mendapatkan pelatihan pemasaran secara online yang akan diberikan dalam kegiatan pengabdian selanjutnya.

d. Mitra perlu mendapatkan pelatihan pembukuan sederhana untuk keuangan usahanya.

Kegiatan pengabdian yang telah dilakukan tentunya memberikan manfaat yang besar terutama bagi pengembangan usaha mitra terutama peningkatan kesejahteraan pelaku usaha tersebut.

\section{KESIMPULAN DAN SARAN}

Kegiatan pengabdian ini telah berhasil dilaksanakan. Keberhasilan ini terlihat dari beberapa dampak positif yang dihasilkan dari kegiatan tersebut antara lain peningkatan kemampuan mitra dalam proses pengemasan produk serta keterampilan mitra dalam membuat merek dagang sederhana. Selain itu, partisipasi penuh yang diberikan oleh mitra juga telah ikut berpartisipasi penuh dalam kegiatan pengabdian ini dari awal observasi hingga tahap evaluasi kegiatan.

Selanjutnya, sebagai tindak lanjut dari kegiatan ini dan saran untuk pengembangan usaha diperlukan pelatihan dan pendampingan terkait pemasaran berbasis online dan pembukuan usaha sehingga kedepannya mitra mampu secara mandiri meamasarkan usahanya tanpa bergantung kepada reseller saja serta dapat mengatur keuangan usahanya dengan lebih baik.

\section{DAFTAR PUSTAKA}

Dinnullah, R. N. I., Nurdin, S., \& Sumadji. (2018). Packing Process Dalam Pelatihan Kemandirian Ukm Kerupuk Bawang Sebagai Upaya Peningkatan Pemasaran Produk. J-ADIMAS (Jurnal Pengabdian Kepada Masyarakat), 6(2), 57-62.

Fitriani, E., Fatimah, S., Mardhiah, D., Selinaswati, S., Hidayat, M., \& Amelia, L. (2020). Pengemasan (Packaging) Rakik Bada Lado Hijau Upaya Peningkatan Pemasaran dan Pelestarian Kuliner Minangkabau. ABDI: Jurnal Pengabdian Dan Pemberdayaan Masyarakat, 2(2), 130-135.

Hariyani, N. (2018). Kerupuk Lemi Bebas Boraks Kajian dari Dosis Natrium Tripolyphospat yang Berbeda. Surabaya: Jurusan Teknologi Pertanian Universitas DR. Soetomo.

Karjo, S. K., Suseno, T. I. P., \& Utomo, A. R. (2015). Pengaruh Proporsi Beras dan Maizena Terhadap Sifat Fisikokimia dan Organoleptik Kerupuk Puli. Jurnal Teknologi Pangan Dan Gizi, 14(1), 1-9. 
Rosiani, N., Basito, \& Widowati, E. (2015). Kajian Karakteristik Sensoris Fisik Dan Kimia Kerupuk Fortifikasi Daging Lidah Buaya (Aloe Vera) Dengan Metode Pemanggangan Menggunakan Microwave. Jurnal Teknologi Hasil Pertanian, $\operatorname{VIII}(2), 84-98$. 